\title{
Prognostic Value of Retinal Nerve Fiber Layer and Ganglion Cell Complex after Optic Chiasmal Decompression
}

\author{
Shaymaa Hassan Salah ${ }^{1 *}$, Ahmed Mohamed Ali2* \\ ${ }^{1}$ Ophthalmology Department, Kasr Al Ainy Hospital, Cairo University, Cairo, Egypt \\ ${ }^{2}$ Neurosurgery Department, Kasr Al Ainy Hospital, Cairo University, Cairo, Egypt \\ Email: *Shaimaa.Sayed@kasralainy.edu.eg, *ahmed.saad@Kasralainy.edu.eg
}

How to cite this paper: Salah, S.H. and Ali, A.M. (2019) Prognostic Value of Retinal Nerve Fiber Layer and Ganglion Cell Complex after Optic Chiasmal Decompression. Open Journal of Modern Neurosurgery, 9, 23-34.

https://doi.org/10.4236/ojmn.2019.91004

Received: October 26, 2018

Accepted: December 10, 2018

Published: December 13, 2018

Copyright (c) 2019 by authors and Scientific Research Publishing Inc. This work is licensed under the Creative Commons Attribution International License (CC BY 4.0).

http://creativecommons.org/licenses/by/4.0/

\begin{abstract}
This paper is an attempt to ascertain the role of the optical coherence tomography by measuring the retinal nerve fiber layer thickness and ganglion cell complex area to predict postoperative visual outcome after chiasmal decompression. 16 eyes scheduled for chiasmal decompression surgery were assessed before and 3 months after surgery with standard automated perimetry and OCT (optical coherence tomography). Preoperative RNFL (retinal nerve fibre layer) thickness and GCC (ganglion cell complex) area were compared with 20 normal control eyes. 13 cases were operated by microscopic assisted endoscopic endonasal transsphenoidal approach; the remaining 3 cases were operated transcranially. Spearman's correlation analysis was used to evaluate the relationship between preoperative RNFL thickness, GCC area, postoperative mean deviation and temporal visual field sensitivity (1/Lambert). Preoperative measurements of RNFL thickness and all GCC area were significantly reduced in the patients compared with normal control. 3 months postoperative evaluation showed improvement of the visual field, but reduction in global and sectorial RNFL thickness except for nasal sector. Moreover, absolute postoperative (not pre-post change) visual field parameters were significantly correlated to preoperative RNFL $(\mathrm{P}=0.00399$ for mean deviation, $\mathrm{P}=$ 0.0023 for temporal sensitivity), GCC thickness $(\mathrm{P}=0.00736$ for mean deviation, $\mathrm{P}=0.0469$ for temporal sensitivity), with FLV (focal loss value) ( $\mathrm{P}=$ 0.0012 for mean deviation, $\mathrm{P}=0.0021$ for temporal sensitivity) showed a higher correlation. Reduced RNFL thickness mainly, and GCC area minimally, were associated with the worst visual field outcome. FLV is a new prognostic value.
\end{abstract}

\section{Keywords}

Optic Chiasm, Decompression Surgery, OCT, Perimetry, Prognosis 


\section{Introduction}

Optic neuropathy due to chiasmal compressive lesion can affect the visual acuity, color vision, and visual field in both eyes [1]. Mechanisms of injury of the optic nerve include damage of retinal ganglion cells and their axons. This injury includes direct insult of conduction along the axon, and/or impairment of the to-and-fro axoplasmic transport [2]. The amount of visual recovery from chiasmal decompression surgery depends on the degree of both anatomical and physiological damages and how much regeneration of retinal ganglion cells and axons will occur [3].

Many studies were used to evaluate the retinal ganglion cells function in chiasmal compressive lesions as visual evoked potential (VEP) [4] [5], pattern electroretinogram (PERG) [6], and photopic negative response (PhNR) [7].

Optical coherence tomography (OCT) now allows cross-sectional scans around the optic nerve head, so it can be used to acquire quantitative data about retinal nerve fiber layer thickness in quadrant fashion around the disc. Studying the ganglion cell complex (GCC) in the macular area is a way to study inner retinal layers that are considered a neurological representation of the retina. OCT can be used to assess retinal ganglion thickness at macula [8]. Previous studies pointed to the correlation between macular OCT and visual field in compression syndrome. Some of them were prospective interventional as our study [3] [9]; others were observational retrospective [10]. Many studies have used OCT to identify nerve fiber thinning in eyes with chiasmal compressive optic neuropathy. They found that visual field defects were always associated with thinning of the retinal nerve fiber layer. These studies investigated only the role of RNFL thickness [11].

The aim of this prospective study is to show the relationship between the thinning of both RNFL, and GCC thickness, and postoperative visual field outcome after chiasmal decompression.

\section{Methods}

Twenty patients diagnosed with chiasmal compression were referred from the Department of Neurosurgery to the Department of Ophthalmlogy, at KasrAlainy Medical Hospital, Cairo University between April 2015 and September 2016. The research adhered to the tenets of the Declaration of Helsinki and was approved by Kasr Alainy Research Ethical Committee Board. Informed consent was obtained. All patients underwent history taking, neurological examination, and radiological investigations in the form of computerized tomography (CT) scan and magnetic resonance imaging (MRI) on the brain. Chiasmal compressive mass was confirmed to each patient by MRI brain, and preoperative field affection using standard automated perimetry (SAP). All patients underwent full ophthalmologic examination on the day of admission to the Department of Neurosurgery, or within one week before operation. That included best corrected visual acuity (BCVA) using Log MAR scale, intraocular pressure (IOP), 
slit-lamp biomicroscopy, gonioscopy, dilated fundus examination, SAP using Humphrey Visual Field Analyzer 2 [HFA2], 24 - 2 program, Swedish Interactive Threshold Algorithm SITA-FAST (Carl Zeiss Meditec, Dublin, CA, USA), and OCT using RTVue FD-OCT system (Optovue, inc. Fremont, CA, USA). Twenty eyes of 20 age-matched controls were recruited from outpatient clinics of the Department of Ophthalmology at Kasr Alainy Hospital, and informed consent was obtained. They showed normal eyes in ophthalmic examination.Eyes in the normal group had RNFL within normative values of machine .Exclusion criteria included any eye disease other than chiasmal compressive lesion; a history of any systemic illness that may affect the retina and optic nerve; reliability es $>30 \%$ false positive, false negative, or fixation loss; a refractive error outside the range of $+/-5$ diopters $(\mathrm{D})$; and any previous neurosurgical management including radiotherapy or surgery; postoperative complications including intracranial hemorrhage or tumor recurrence. Sixteen patients met the inclusion criteria and sixteen eyes only were analyzed. Four patients did not meet the inclusion criteria, because of incomplete resection of tumor (one patient), death (one patient), and not completing the follow-up (two patients). In the sixteen patients, the eye with lesser preoperative visual field defect was selected. Three months after neurosurgical operation (transsphenoidal or transcranial) same examination and investigations were done.

Brain imaging:

Anterior visual pathway and chiasmal compression were confirmed using MRI brain, and 4 vessels angiography was done when needed to outline the relation between tumors and vascular tree. Tumor removal was confirmed three months after surgery in regular follow up of patients using CTbrain and MRI brain when needed (Figure 1).

Optical Coherence Tomography:

SD-OCT was done using the RTVueFD-OCT system (software version \#6, 11, 0, 12; Optovue, inc. Fremont, CA, USA). The RTVue-OCT uses a near-infrared light-source at $840 \mathrm{~nm}$. The standard glaucoma protocol was used in this study including RNFL, ONH and macular GCC [12]. The optical principles of the OCT have been described elsewhere [13].

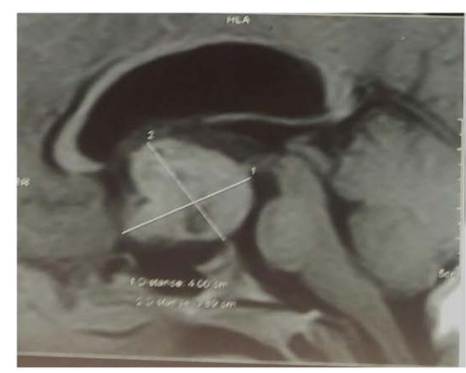

(a)

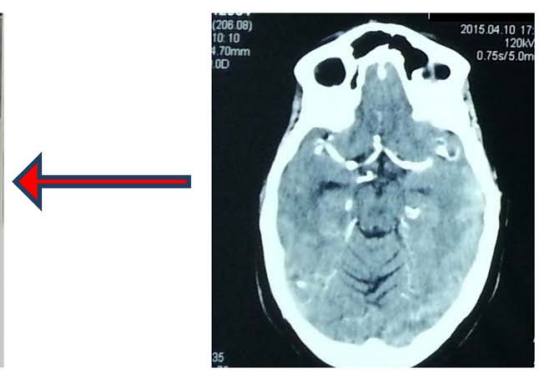

(b)

Figure 1. Brain imaging of a patient with pituitary adenoma. (a): shows preoperative sagittal section (with arrow) in MRI brain with contrast; (b): postoperative axial section in CT brain with contrast of same patient. 
Optic nerve head scan:

This consists of a $3 \mathrm{D}$ optic disc scan for the disc margin that automatically determines the retinal pigment epithelium margins, then an $\mathrm{ONH}$ scan to measure the optic disc parameters and RNFLT over a circle of diameter $3.45 \mathrm{~mm}$, centered on the pre-defined disc [12]. It consists of 12 radial lines and six concentric rings, which are used to create an RNFL thickness map. The parameters calculated are the average RNFL thickness in the temporal, superior, nasal, and inferior quadrant as well as the overall average along the entire measurement circle measured in micrometers.

Ganglion cell complex scan:

The GCC thickness is measured from the ILM (internal limiting membrane) to the IPL (inner plexiform layer) boundary. The parameters obtained include the superior (above horizontal meridian), inferior (below horizontal meridian) and average thickness measured in micrometers. The results are categorized using color codes as in RNFL thickness. Three main maps are displayed on the printout: the thickness map, deviation map, and the significance map. A new parameter is global loss volume (GLV) that measures the average amount of GCC loss over the entire GCC map, based on the fractional deviation (FD) map. Focal Loss Volume (FLV) is the total sum of statistically significant GCC volume loss divided by the GCC map area [14].

Standard automated perimetry:

Standard automated perimetry was done using SITA-Standard 24 - 2 of the Humphrey Field Analyzer program (Carl Zeiss Meditec) with a Goldmann size III stimulus on a 31.5-apostilb background. Perimetry was performed within 2 weeks of OCT testing. The following parameters were recorded: mean deviation $(\mathrm{dB})$ and pattern standard deviation (PSD) in $\mathrm{dB}$. The primary analysis involved dividing the VF data into nasal and temporal hemifields. The criteria for an abnormal hemifield was at least three significantly depressed $(P<5 \%)$ non-edge-contiguous points on the $\mathrm{PD}$ plot, with two of these points $\mathrm{P}<1 \%$, not including those in contact with blind spot. The average temporal hemifield sensitivity was calculated in $1 /$ Lambert scale and then analyzed. Visual field sensitivity was recorded for each point using the decibel (dB) [10-log (1/Lambert)]. The unlogged $1 /$ Lambert $\{1 / \mathrm{L}\}$ at each test location was calculated by dividing the decibel unit by 10 and then unlogging it [3].

Statistical analysis:

Mann-Whitney U test was used to compare normal control group with preoperative SAP and OCT results. Wilcoxon signed-ranks test was used to compare preoperative SAP, OCT results with those after 3 months postoperative. Spearman correlation and then linear regression analyses were used to assess the strength of possible associations between OCT parameters (RNFL thickness and GCC) and SAP parameters (MD, and temporal sensitivity). In regression analysis, postoperative temporal visual field sensitivity was considered the dependent variable and preoperative SD-OCT measurements were considered independent variables. Regression goes beyond correlation by adding prediction capabilities. 
All tests were two-tailed, and $\mathrm{P}<0.05$ was considered was considered statistically significant.

\section{Results}

\section{Descriptive data:}

Thirteen patients were operated by microscopic assisted endoscopic endonasal transsphenoidal approach for better visualization of optic apparatus. The remaining 3 cases were operated transcranially through pterional approach. All cases had postoperative CT scan and MRI brain when needed. Fourteen cases were discharged within 7 days after the operation. Two cases had diabetes insipidus and had to stay for 3 more days. All cases had uneventful surgery without major complications. Chiasma was prefixed in 10 cases and postfixed in 6 cases. The average age of patients was $44+/-6.78$ years, nine males and four females. The average age of control group was $42+/-5.5$ years, twelve males and eight females. Patients had pituitary adenoma (thirteen), craniopharyngioma (two), and meningioma (one).

\section{Visual Fields Outcome:}

MD showed improvement from median $-15.735 \mathrm{~dB}$ (range $-31.07,-2.11$ ) before surgery to median $-9.02 \mathrm{~dB}$ (range $-25.34,-1.4$ ) at 3 months after surgery. Temporal visual field sensitivity also showed improvement from median 1.915 (1/L) (range 1, 639.653) to median 198.458 (1/L) (range 1.933, 801.342) (Table 1).

\section{OCT outcome:}

Average and sectional circumpapillary RNFL thickness (cpRNFL) measured preoperatively were compared to normal control showing a significant reduction. Also average GCC around fovea and GCC thickness in both superior and inferior halves of the macula were significantly reduced compared to normal control. FLV and GLV also showed a significant decrease.

RNFL thickness was reduced in average and in all sectors except nasal which showed insignificant increase at 3 months after surgery. The decrement of decrease was significant in only temporal quadrant $(\mathrm{P}=0.0131)$, and average $(\mathrm{P}=$ 0.0168). GCC thickness continued to decline at 3 months after surgery but this decline was insignificant except for the inferior GCC that showed significant decrease $(P=0.0232)$. Both GLV and FLV showed an insignificant decrease after three months Table 1 and Figure 2.

The preoperative OCT findings were compared to the absolute postoperative field parameters. A positive correlation was found between the average, inferior, superior, temporal, nasal RNFL, and MD, temporal sensitivity. The strongest positive correlation was between preoperative superior RNFL and postoperative field parameters (Figure 3(a)). A positive moderate correlation was found only between inferior, average GCC and field parameters (Figure 3(b)). Negative strong correlation was found between FLV, GLV and MD, and the temporal sensitivity (Figure $3(\mathrm{c})$ and Table 2 ). The preoperative OCT findings were compared to the preoperative-postoperative change infield parameters. No statistical correlation was found between the average, inferior, superior, temporal, 
Table 1. Findings of best corrected visual acuity, retinal nerve fiber thickness, and ganglion cell complex in the sixteen patients compared with twenty control group preoperatively and then preoperative compared to postoperative.

\begin{tabular}{|c|c|c|c|c|c|}
\hline Variable & $\begin{array}{l}\text { Control } \\
\text { Median } \\
\text { (range) }\end{array}$ & $\begin{array}{c}\text { Preoperative } \\
\text { Median } \\
\text { (range) }\end{array}$ & $\begin{array}{l}\text { P value } \\
\text { (Control } \\
\text { vs. pre) }\end{array}$ & $\begin{array}{c}\text { Post } 3 \text { months } \\
\text { Median } \\
\text { (range) }\end{array}$ & $\begin{array}{c}\text { P value } \\
\text { (Prevs. } 3 \text { mo.) }\end{array}$ \\
\hline $\begin{array}{c}\text { VA } \\
\text { (Log MAR) }\end{array}$ & 0.00 & $\begin{array}{c}0.69 \\
(1,0.3)\end{array}$ & 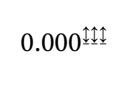 & $\begin{array}{c}0.24 \\
(0.78,0)\end{array}$ & $0.00044^{\cdots}$ \\
\hline \multicolumn{6}{|c|}{ Visual field test } \\
\hline $\mathrm{MD}(\mathrm{dB})$ & $\begin{array}{c}-1.5 \\
(-1.46,1.5)\end{array}$ & $\begin{array}{c}-15.735 \\
(-31.07,-2.11)\end{array}$ & $0.000^{1 \pm \Perp}$ & $\begin{array}{c}-9.02 \\
(-25.34,-1.4)\end{array}$ & $0.0151^{\bullet}$ \\
\hline $\begin{array}{c}\text { Temporal } \\
\text { hemifield }(1 / \mathrm{L})\end{array}$ & $\begin{array}{c}1150 \\
(965,1447)\end{array}$ & $\begin{array}{c}1.915 \\
(1,639.653)\end{array}$ & $0.000^{\underline{1} \underline{1} \underline{1}}$ & $\begin{array}{c}198.458 \\
(1.933,801.342)\end{array}$ & $0.00132 \bullet$ \\
\hline \multicolumn{6}{|c|}{ Retinal nerve fiber layer thickness (um) } \\
\hline Superior & $\begin{array}{c}110.08 \\
(100.02,126.37)\end{array}$ & $\begin{array}{c}73.275 \\
(51.41,109.45\end{array}$ & $0.0001 \underline{1 \Perp \Perp 1}$ & $\begin{array}{c}\mathbf{7 0 . 7 2} \\
(49.36,125.67)\end{array}$ & 0.174 \\
\hline Inferior & $\begin{array}{c}114.56 \\
(99.65,125.57)\end{array}$ & $\begin{array}{c}\mathbf{7 8 . 8 2 5} \\
(56.48,111.7)\end{array}$ & $0.000^{1 \pm \Perp 1}$ & $\begin{array}{c}77.185 \\
(57.67,109.78)\end{array}$ & 0.254 \\
\hline nasal & $\begin{array}{c}85 \\
(74.5,99.5)\end{array}$ & $\begin{array}{c}\mathbf{5 4 . 5} \\
(28.5,87.5)\end{array}$ & $0.000^{ \pm \pm 上}$ & $\begin{array}{c}55.25 \\
(28.5,95)\end{array}$ & 0.159 \\
\hline temporal & $\begin{array}{c}\mathbf{8 8 . 5} \\
(72,102.5)\end{array}$ & $\begin{array}{c}\mathbf{5 6 . 5} \\
(35,117.5)\end{array}$ & 0.00016 站 & $\begin{array}{c}51.75 \\
(35,104.5)\end{array}$ & $0.0131^{\bullet}$ \\
\hline average & $\begin{array}{c}113.16 \\
(99.83,122.42)\end{array}$ & $\begin{array}{c}74.255 \\
(59.6,116)\end{array}$ & $0.000^{1 \pm \Perp}$ & $\begin{array}{c}71.295 \\
(57.7,116.14)\end{array}$ & $0.0168^{\bullet}$ \\
\hline \multicolumn{6}{|c|}{ Ganglion cell complex thickness (um) } \\
\hline superior & $\begin{array}{c}102.44 \\
(88.9,115.75)\end{array}$ & $\begin{array}{c}\mathbf{8 6 . 2 2} \\
(70.13,101.82)\end{array}$ & $0.000^{ \pm \Perp 1}$ & $\begin{array}{c}\mathbf{8 5 . 0 6} \\
(66.74,98.38)\end{array}$ & 0.254 \\
\hline inferior & $\begin{array}{c}100.32 \\
(90.5,116.22)\end{array}$ & $\begin{array}{c}\mathbf{8 2 . 9 3} \\
(63.9,95.7)\end{array}$ & $0.000^{1 \pm 上}$ & $\begin{array}{c}84.015 \\
(68.8,98.23)\end{array}$ & $0.0232^{\circ}$ \\
\hline average & $\begin{array}{c}101.375 \\
(90,115.98)\end{array}$ & $\begin{array}{c}\mathbf{8 4 . 5 3} \\
(68.95,97.67)\end{array}$ & $0.000^{1 \pm \Perp}$ & $\begin{array}{c}83.32 \\
(67.77,98.3)\end{array}$ & 0.4593 \\
\hline \multicolumn{6}{|c|}{ Loss Volume (\%) } \\
\hline Focal & $\begin{array}{c}\mathbf{0 . 1 0 4 5} \\
(0.866,0.004)\end{array}$ & $\begin{array}{c}\mathbf{6 . 8 4 7} \\
(13.075,0.244)\end{array}$ & 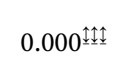 & $\begin{array}{c}7.159 \\
(10.904,1.434)\end{array}$ & 0.0703 \\
\hline General & $\begin{array}{c}2.348 \\
(8.238,0.142)\end{array}$ & $\begin{array}{c}14.151 \\
(29.264,3.109)\end{array}$ & $0.000^{ \pm \underline{1} \pm}$ & $\begin{array}{c}14.2605 \\
(31.946,4.671)\end{array}$ & 0.280 \\
\hline
\end{tabular}

Abbreviations: VA, visual acuity, $\mathrm{MD}$, mean deviation, range(min, max), $\mathrm{dB}$, decibel, 1/L, 1/Lambert, um,

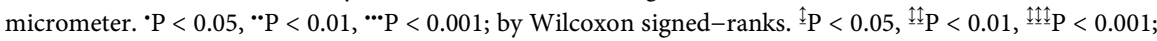
by Mann-Whitney.

nasal RNFL, and field parameters change. No statistical correlation was found between the average, superior, inferior GCC, FLV, or GLV and field parameters change (Table 3). Linear regression analysis was used to confirm predictors between preoperative OCT variables and absolute postoperative field parameters. Superior RNFL and FLV were the strongest predictors to postoperative both mean deviation and temporal sensitivity. Inferior GCC was the only moderately 


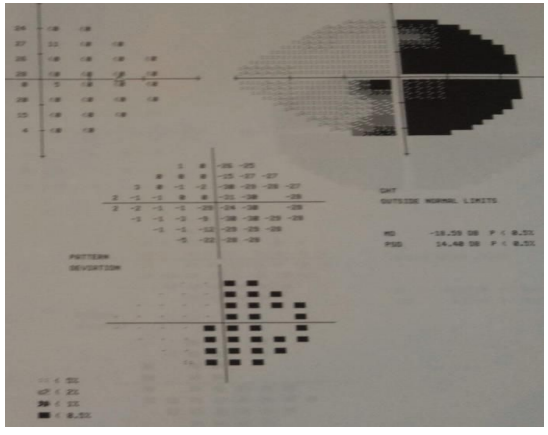

I

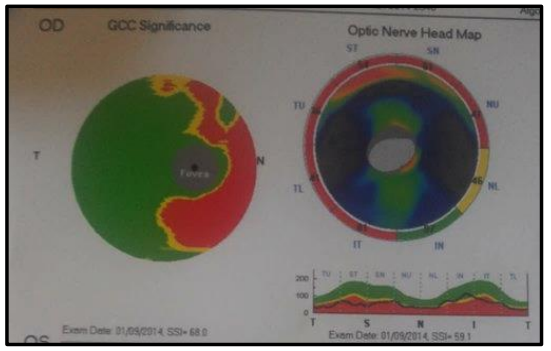

I

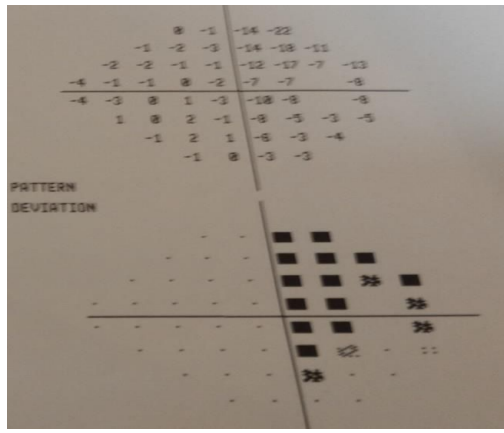

II

(a)

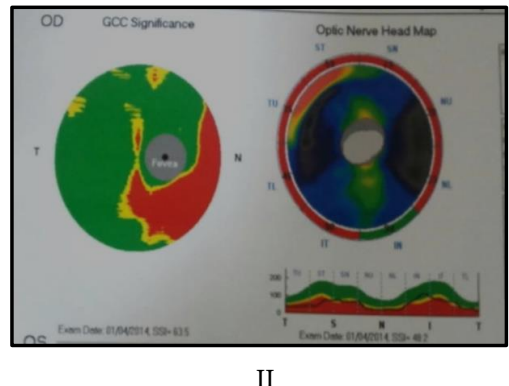

II

(b)

Figure 2. (a) SAP of 48 years male with pituitary adenoma and underwent transsphenoidalad enedectomy. I: Preoperative visual field of right eye with $\mathrm{MD}=-17 \mathrm{~dB}$ and temporal defect that respects vertical meridian, II: postoperative field of same eye with MD improved to $-7.59 \mathrm{~dB}$ after three months showing regression of inferior quadrant of temporal field defect; (b): cpRNFL and macular GCC of same patient in Figure 2(a). I: Preoperative RNFL thickness map shows extensive reduction in all sectors (red), with GCC significance map showing less extensive loss II: three months after surgery showing improvement of superior GCC and worsening in RNFL thickness.

Table 2. Spearman's correlation coefficients and regression analysis between preoperative OCT measurements and absolute postoperative visual field measurements.

\begin{tabular}{|c|c|c|c|c|c|c|c|c|}
\hline \multirow{2}{*}{$\begin{array}{c}\text { Variables } \\
\text { (Preoperative } \\
\text { Values) }\end{array}$} & \multicolumn{4}{|c|}{$\begin{array}{c}\text { Postoperative Mean deviation (dB) } \\
\text { Spearman's Linear Regression }\end{array}$} & \multicolumn{4}{|c|}{$\begin{array}{l}\text { Postoperative Temporal sensitivity (1/L) } \\
\text { Spearman's Linear Regression }\end{array}$} \\
\hline & $\mathbf{R}$ & $\mathbf{P}$ & $\mathbf{R}$ & $\mathbf{P}$ & $\mathbf{R}$ & $\mathbf{P}$ & $\mathbf{R}$ & $\mathbf{P}$ \\
\hline \multicolumn{9}{|c|}{ RNFL thickness } \\
\hline Superior & 0.757 & $0.0007^{\star * *}$ & 0.676 & $0.00399^{* * *}$ & 0.645 & $0.007^{\star \star}$ & 0.704 & $0.0023^{\star *}$ \\
\hline Inferior & 0.651 & $0.0063^{\star *}$ & 0.625 & $0.00963^{* *}$ & 0.610 & $0.0119^{*}$ & 0.72 & $0.0016^{* *}$ \\
\hline Nasal & 0.543 & $0.0297^{\star}$ & 0.567 & $0.02199^{*}$ & 0.542 & $0.0302^{\star}$ & 0.561 & $0.0236^{*}$ \\
\hline temporal & 0.638 & $0.0078^{\star}$ & 0.497 & $0.04989^{*}$ & 0.541 & $0.0306^{\star}$ & 0.526 & $0.0359^{\star}$ \\
\hline Average & 0.689 & $0.0032^{\star \star}$ & 0.685 & $0.00341^{* *}$ & 0.596 & $0.0148^{*}$ & 0.746 & $0.0009^{\star * *}$ \\
\hline \multicolumn{9}{|c|}{ GCC thickness } \\
\hline Superior & 0.316 & 0.231 & 0.401 & 0.12301 & 0.304 & 0.2518 & 0.24 & 0.3707 \\
\hline Inferior & 0.598 & $0.0145^{\star}$ & 0.641 & $0.00736^{* *}$ & 0.497 & $0.0499^{*}$ & 0.503 & $0.0469^{*}$ \\
\hline Average & 0.546 & $0.0287^{*}$ & 0.554 & $0.02587^{\star}$ & 0.483 & $0.0583^{*}$ & 0.395 & 0.1299 \\
\hline \multicolumn{9}{|c|}{ Loss Volume } \\
\hline FLV & -0.764 & $0.0006^{\star * *}$ & -0.735 & $0.0012^{\star \star}$ & -0.764 & $0.0006^{* * *}$ & -0.709 & $0.0021^{\star *}$ \\
\hline GLV & -0.623 & $0.0099^{\star *}$ & -0.657 & $0.0057^{\star *}$ & -0.589 & $0.0164^{*}$ & -0.560 & $0.0241^{*}$ \\
\hline
\end{tabular}

${ }^{\star} \mathrm{P}<0.05 ;{ }^{* *} \mathrm{P}<0.01 ;{ }^{* * *} \mathrm{P}<0.001$. 


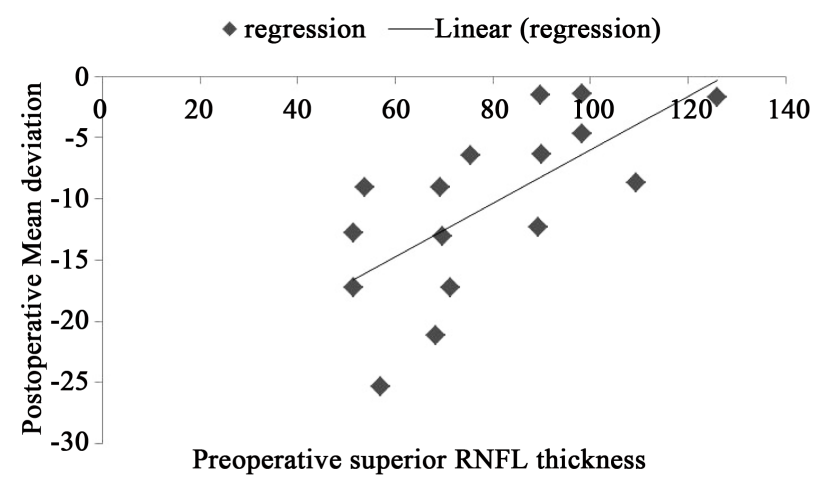

$R=0.676 ; P=0.20399$

- regression — Linear (regression)

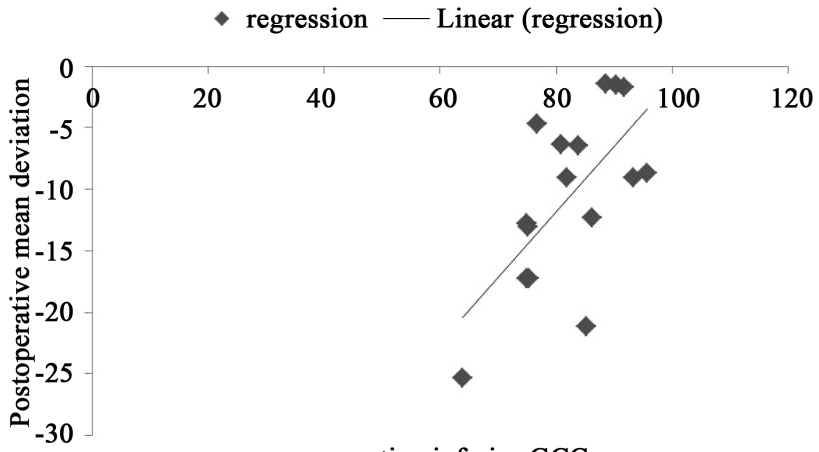

preoperative inferior GCC

$\mathrm{R}=\mathbf{0 . 6 4 1} ; \mathbf{P}=\mathbf{0 . 0 0 7 3 6}$

Linear (regression)

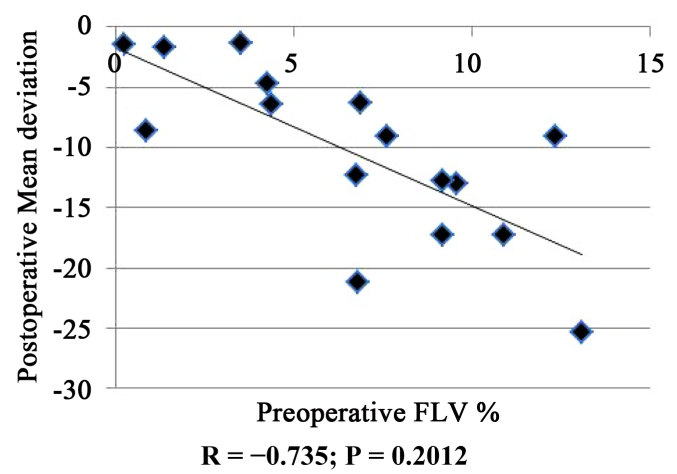

- regression — Linear (regression)

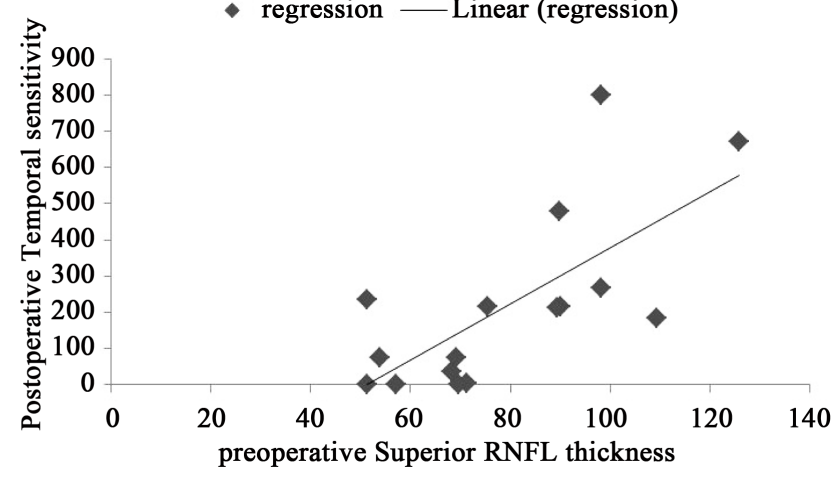

$R=0.704 ; P=0.0023$

(a)

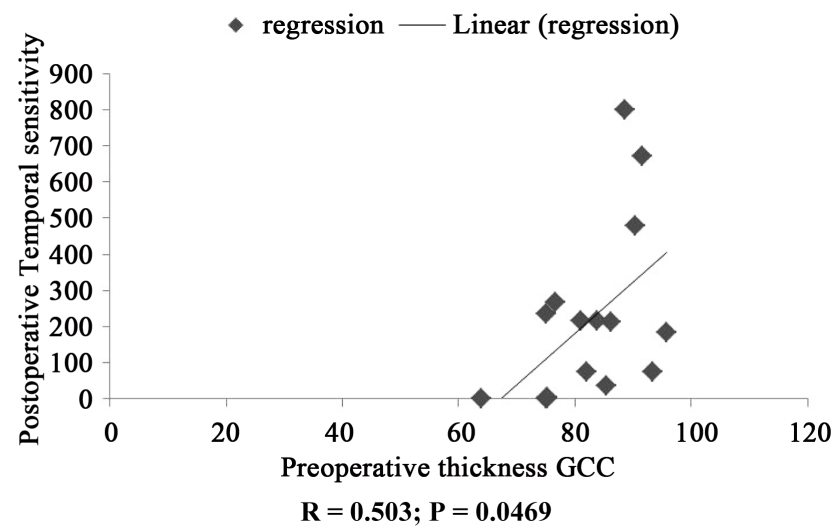

(b)

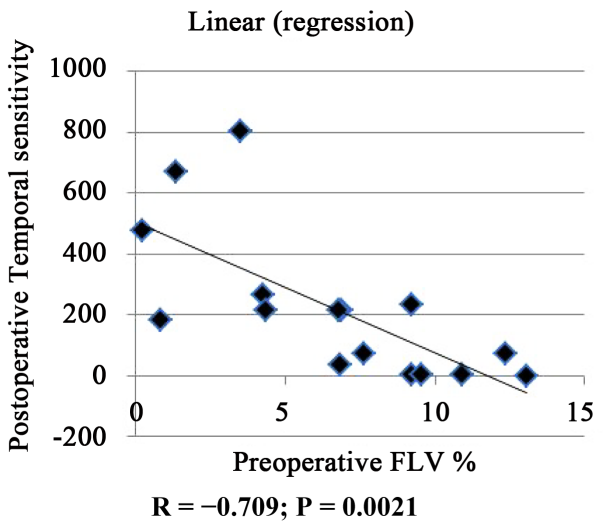

(c)

Figure 3. Scatterplot between postoperative MD, temporal sensitivity and (a) preoperative superior RNFL thickness; (b) preoperative inferior GCC; and (c) Preoperative FLV.

significant predictor to both field variables. As no statistical correlation was found between the preoperative OCT variables and the pre-postoperative change in field, regression analysis was not carried out (Table 3).

\section{Discussion}

Chiasmal mass causes compression mainly to temporal visual hemifield that corresponds to nasal hemiretinal axons which in turn enter the optic disc 
Table 3. Spearman's correlation between OCT variables and preoperative to postoperative changes in temporal sensitivity and mean deviation.

\begin{tabular}{|c|c|c|c|c|}
\hline \multirow[t]{2}{*}{$\begin{array}{l}\text { Preoperative } \\
\text { OCT Variables }\end{array}$} & \multicolumn{2}{|c|}{$\begin{array}{l}\text { Pre-Post CHANGE in } \\
\text { Temporal sensitivity (1/L) } \\
\text { Spearman's Correlation }\end{array}$} & \multicolumn{2}{|c|}{$\begin{array}{l}\text { Pre-Post CHANGE in } \\
\text { Mean deviation (dB) } \\
\text { Spearman's Correlation }\end{array}$} \\
\hline & $\mathbf{R}$ & $\mathbf{P}$ & $\mathbf{R}$ & $\mathbf{P}$ \\
\hline \multicolumn{5}{|c|}{ RNFL thickness } \\
\hline Superior & 0.2003 & 0.45701 & -0.22533 & 0.40142 \\
\hline Inferior & 0.24742 & 0.35554 & -0.30486 & 0.25092 \\
\hline Nasal & 0.10751 & 0.69188 & -0.37408 & 0.15347 \\
\hline temporal & 0.25497 & 0.34057 & -0.1297 & 0.63212 \\
\hline Average & 0.17526 & 0.5162 & -0.27393 & 0.30458 \\
\hline \multicolumn{5}{|c|}{ GCC thickness } \\
\hline Superior & 0.16642 & 0.53789 & -0.09426 & 0.72843 \\
\hline Inferior & 0.18262 & 0.49843 & -0.11929 & 0.65991 \\
\hline Average & 0.24742 & 0.35554 & -0.10162 & 0.70805 \\
\hline \multicolumn{5}{|c|}{ Loss Volume } \\
\hline$F L V$ & -0.40354 & 0.12115 & 0.3785 & 0.14828 \\
\hline$G L V$ & -0.31959 & 0.22758 & 0.2268 & 0.39827 \\
\hline
\end{tabular}

All data are statistically insignificant $\mathrm{P}>0.05$.

through mainly nasal, and temporal sectors [3]. With few axons also enter through superior and inferior sectors. Among nasal hemiretinal axons, the papillomacular bundle reaches the disc through the temporal quadrant. The axons responsible for the nasal visual hemifield enter optic disc through superior and inferior sectors only. The OCT can give accurate measurements of circumpapillary retinal nerve fiber layer thickness [15]. Danesh-Meyer et al. [16], followed by Jacob et al. [8] were first to describe the structure-function relationship in chiasmal compressive optic neuropathy. Both studies found a significant reduction in global and sectorial RNFL thickness, with both temporal and nasal sectors having the greatest reduction. In this study, we have found significant reduction in global and sectorial preoperative RNFL thickness, but with nasal sector having the greatest percentage of this reduction. This is against what Moon et al. [9] had proven in their study as they have found no significant reduction in the nasal preoperative RNFL sector. In the same study by Moon et al. [9], they assessed the preoperative RNFL thickness in all quadrants and found them correlated to the postoperative visual field parameters (temporal sensitivity and $\mathrm{MD})$, except nasal sector. The temporal RNFL showed the strongest correlation. They attributed significant temporal sector correlation due to the presence of papillomacular bundle that is severely affected in chiasmal compression syndrome. In this study, we found that preoperative RNFL thickness in all qua- 
drants was correlated to postoperative field changes, but temporal RNFL showed the least correlation which is against results by Moon et al. The superior RNFL thickness showed the mostly correlated quadrant to postoperative field changes followed by inferior, nasal and then temporal RNFL. This may be a prognostic marker as superonasal, inferonasal RNFL thickness reflects the superotemporal and inferotemporal field changes respectively, and these are the mostly affected parts of the field of the chiasmal compressive lesion. In another study by Moon et al. [3], they compared preoperative and postoperative RNFL reduction, and have found an insignificant reduction in temporal postoperative RNFL thickness. In this study, we compared preoperative and postoperative RNFL reduction and we have found a global and sectorial reduction in postoperative measurements with a significant reduction in both average and temporal sectors. In Danesh-Mayer [11], they divided their patients into two groups: normal and thinned RNFL thickness compared to normative data of OCT software and not a normal group as this study. Their study showed cut-off value below which correlation to the pre-post change in MD is insignificant. In our study, the preoperative OCT value had an insignificant correlation to the pre-post change in MD. RNFL thinning indicates atrophy of optic nerve axons secondary to compression [8], but does not mean that retinal ganglion cells are lost. In this study, we measured the GCC as this reflects a loss in three layers, 1) the retinal nerve fiber layer which is made up of the ganglion cell axons, 2) the ganglion cell layer (GCL) consists of the ganglion cell bodies, and 3) the inner-plexiform layer (IPL) containing the ganglion cell dendrites. All the three layers were collectively known as the ganglion cell complex (GCC). Preoperatively measured inferior ganglion cell complex values in this study were correlated significantly with the postoperative visual field, but not as significantly as the preoperative RNFL thickness. Moon et al. [9] showed that GCC measurements had a higher correlation than RNFL thickness with postoperative field changes. In our study a new parameter evolves which is the focal loss volume that showed significant correlation higher than both GCC thickness and RNFL thickness.

\section{Limitations of the Study}

Our study had some limitations including the small number of participants, and short term follow-up, as longer follow-up of 6 - 9 months may be required.

\section{Conclusion}

Evident structural/functional relationship (OCT/VF) is present. Reduced RNFL thickness mainly and GCC area minimally, were associated with the worst visual field outcome. FLV is of a new prognostic value.

\section{Conflicts of Interest}

The authors declare no conflicts of interest regarding the publication of this paper. 


\section{References}

[1] Gnanalingham, K.K., Bhattacharjee, S., Pennington, R., Ng, J. and Mendoza, N. (2005) The Time Course of Visual Field Recovery Following Transsphenoidal Surgery for Course of Visual Field Recovery Following Transphenoidal Surgery for Pituitary Adenomas: Predictive Factors for a Good Outcome. Journal of Neurology, Neurosurgery, and Psychiatry, 76, 415-419. https://doi.org/10.1136/jnnp.2004.035576

[2] Li, B., Barnes, G.E. and Holt, W.F. (2005) The Decline of the Photopic Negative Response (PhNR) in the Rat after Optic Nerve Transaction. Documenta Ophthalmologica, 111, 23-31. https://doi.org/10.1007/s10633-005-2629-8

[3] Moon, C.H., Hwang, S.C., Ohn, Y.-H. and Park, T.K. (2011) The Time Course of Visual Field Recovery and Changes of Retinal Ganglion Cells after Optic Chiasmal Decompression. Investigative Ophthalmology \& Visual Science, 52, 7966-7973. https://doi.org/10.1167/iovs.11-7450

[4] Chacko, A.G., Babu, K.S. and Chandy, M.J. (1996) Value of Visual Evoked Potential Monitoring during Trans-Sphenoidal Surgery. British Journal of Neurosurgery, 10, 275-278. https://doi.org/10.1080/02688699650040133

[5] Brecelj, J., Denislic, M. and Skrbec, M. (1989) Visual Evoked Potential Abnormalities in Chiasmal Lesions. Documenta Ophthalmologica, 73, 139-148. https://doi.org/10.1007/BF00155032

[6] Monteiro, M.L., Cunha, L.P., Costa-Cunha, L.V., Maia Jr, O.O. and Oyamada, M.K. (2009) Relationship between Optical Coherence Tomography, Pattern Electroretinogram, and Automated Perimetry in Eyes with Temporal Hemianopia from Chiasmal Compression. Investigative Ophthalmology \& Visual Science, 50, 3535-3541. https://doi.org/10.1167/iovs.08-3093

[7] Machida, S., Raz-Prag, D., Fariss, R.N., Sieving, P.A. and Bush, R.A. (2008) Photopic ERG Negative Response from Amarcine Cell Signaling in RCS Rat Retinal Degeneration. Investigative Ophthalmology \& Visual Science, 49, 442-452. https://doi.org/10.1167/iovs.07-0291

[8] Jacob, M., et al. (2009) Predicting Visual Outcome after Treatment of Pituitary Adenoma with Optical Coherence Tomography. American Journal of Ophthalmology, 147, 64-70. https://doi.org/10.1016/j.ajo.2008.07.016

[9] Moon, H.C., Hwang, S.C., Kim, B.-T., Ohn, Y.-H. and Park, T.K. (2011) Visual Prognostic Value of Optical Coherence Tomography and Photopic Negative Response in Chiasmal Compression. Investigative Ophthalmology \& Visual Science, 52, 8527-8533. https://doi.org/10.1167/iovs.11-8034

[10] Monteiro, M.L., Costa-Cunha, L.V., Cunha, L.P. and Malta, R.F. (2010) Correlation between Macular and Retinal Nerve Fiber Layer Fourier-Domain OCT Measurements and Visual Field Loss in Chiasmal Compression. Eye, 24, 1382-1390.

[11] Danesh-Meyer, H.V., et al. (2008) In Vivo Retinal Nerve Fiber Layer Thickness Measured by Optical Coherence Tomography Predicts Visual Recovery after Surgery for Parachiasmal Tumors. Investigative Ophthalmology \& Visual Science, 49, 1879-1885. https://doi.org/10.1167/iovs.07-1127

[12] Garas, A., Vargha, P. and Holló, G. (2011) Diagnostic Accuracy of Nerve Fiber Layer, Macular Thickness and Optic Disc Measurements Made with the RTVue-100 Optical Coherence Tomography to Detect Glaucoma. Eye, 25, 57-65. https://doi.org/10.1038/eye.2010.139

[13] Schuman, J.S., et al. (1996) Reproducibility of Nerve Fiber Layer Thickness Measurements Using Optical Coherence Tomography. Ophthalmology, 103, 1889-1898. 
https://doi.org/10.1016/S0161-6420(96)30410-7

[14] Rao, H.L., Babu, J.G., Addepalli, U.K., Senthil, S. and Garudadri, C.S. (2012) Retinal Nerve Fiber Layer and Macular Inner Retina Measurements by Spectral Domain Optical Coherence Tomography in Indian Eyes with Early Glaucoma. Eye, 26, 133-139. https://doi.org/10.1038/eye.2011.277

[15] Kanamori, A., et al. (2004) Optical Coherence Tomography Detects Characteristic Retinal Nerve Fiber Layer Thickness Corresponding to Band Atrophy of the Optic Discs. Ophthalmology, 111, 2278-2283.

https://doi.org/10.1016/j.ophtha.2004.05.035

[16] Danesh-Meyer, H.V., et al. (2006) Relationship between Retinal Nerve Fiber Layer and Visual Field Sensitivity as Measured by Optical Coherence Tomography in Chiasmal Compression. Investigative Ophthalmology \& Visual Science, 47, 4827-4835.

https://doi.org/10.1167/iovs.06-0327 